\title{
PERCEPÇÕES SOBRE A QUALIDADE DOS SERVIÇOS E PRODUTOS INFORMACIONAIS DE UMA BIBLIOTECA ESPECIALIZADA EM AGROPECUÁRIA: ESTUDO DE CASO ${ }^{1}$
}

\author{
Cláudia Simone Felipe \\ Bibliotecária do Instituto de Assistência Técnica e Extensão Rural do Rio Grande do Norte \\ Emater/RN \\ claufelipe82@gmail.com
}

Resumo

\begin{abstract}
A qualidade dos serviços e produtos é importante em qualquer ramo de atividade. Nas bibliotecas não é diferente. Para se chegar a esse entendimento fez-se importante trazer para este artigo conceitos de biblioteca, qualidade, qualidade total e biblioteca especializada. Logo em seguida são elencados aspectos históricos e de localização sobre a biblioteca nacional de agricultura, buscando informar qual a principal fonte de acervos sobre agropecuária no Brasil. E no estado do Rio Grande do Norte, realizou-se estudo de caso tendo como principal fim verificar se uma biblioteca especializada em agropecuária consegue atingir seu principal objetivo: atendimento das necessidades informacionais do público-alvo, com serviços e produtos de qualidade. Utilizou-se como parte da metodologia, aplicação de questionários a 55 (cinquenta e cinco) servidores pertencentes ao quadro de pessoal da autarquia que mantém a unidade de informação em tela, além de pesquisa bibliográfica/eletrônica. A análise estatística foi por meio de proporções. Como resultado constatou-se que a qualidade na prestação de serviços e produtos informacionais apresentou-se parcialmente satisfatória. $\mathrm{O}$ estudo desse caso torna-se relevante porque é marco para rever e melhorar processos de trabalho com vistas maximizar o uso de serviços e produtos informacionais.
\end{abstract}

Palavras-chave: Qualidade total - Serviços e produtos informacionais. Biblioteca especializada Agropecuária.

\section{INTRODUÇÃO}

Desde a antiguidade, bibliotecas são centros do saber humano. Naquele tempo o acesso a elas era privilégio de poucos, pois somente os monges tinham o conhecimento produzido pelos homens. Mas, o que são bibliotecas?

Segundo o novo dicionário Aurélio da língua portuguesa (FERREIRA, 1986, p.253) entre outros conceitos "biblioteca significa coleção pública ou privada de livros $e$ documentos congêneres, organizada para o estudo, leitura e consulta". Para o Aurélio, a palavra é originada do grego bibliothéke e chegou até nós pelo latim bibliotheca.
$\mathrm{Na}$ contemporaneidade refere-se à compilação de dados registrados nos mais variados suportes informacionais, dos tradicionais aos modernos. O exemplo atual do avanço desses suportes é o $e$-book, livro na forma eletrônica para democratizar a informação e a leitura.

Porém, muitas pessoas só utilizam as bibliotecas quando estão nos cursos de graduação, o que gera certa dificuldade na adaptação ao cotidiano acadêmico, este rico em leituras, produções e interpretações textuais para a prática científica. Quando são bibliotecas dependentes do orçamento público, na maioria dos casos, enfrentam sérias

\footnotetext{
${ }^{1}$ Artigo antes apresentado ao Curso de Especialização em Gestão Estratégica em Sistema de Informação, do Departamento de Biblioteconomia, do Centro de Ciências Sociais Aplicadas, da Universidade Federal do Rio Grande do Norte sob a orientação da Prof ${ }^{a}$ MSc. Penha Machado de Medeiros, como requisito parcial para o título de especialista.
} 
dificuldades para desenvolver o seu propósito dentro da missão institucional, transformandose em ambientes esquecidos, verdadeiros depósitos que são utilizados para armazenar objetos totalmente fora da realidade de uma biblioteca.

Nesse sentido, muitas unidades informacionais são desativadas, seus acervos são destruídos e não há contratação de pessoal especializado para contribuir com o desenvolvimento de coleções e a conservação desses centros do saber.

No entanto, a biblioteca não deve ser vista somente como um setor isolado e estático. E sim contribuir para que seu público potencial tenha acesso à informação mesmo sem precisar frequentá-la. Sendo assim, faz-se necessário utilizar além dos métodos tradicionais, todos os recursos que a tecnologia disponibiliza para incentivar o uso de produtos e serviços disponíveis.

A qualidade dos serviços e produtos informacionais nas bibliotecas depende do grau de satisfação da comunidade atendida. Nesse contexto, buscou-se descobrir porque o acervo de uma biblioteca do ramo agropecuário é pouco utilizado bem como detectar as formas para atrair o público, e os meios adicionais para disseminar informações relativas aos serviços/produtos oferecidos pela biblioteca.

Com efeito, procurou-se saber por meio do estudo de caso, se a referida biblioteca atende às necessidades informacionais dos servidores de sua instituição mantenedora, com o propósito de levantar bases para melhorar a gestão da qualidade dos produtos/serviços oferecidos.

Como objetivos específicos, buscou-se: a) verificar o nível de satisfação dos usuários e qualidade dos serviços/ produtos prestados, pelos determinantes confiabilidade, rapidez, tangibilidade, empatia, flexibilidade e outros. b) identificar a adequação dos recursos disponíveis para a melhoria da qualidade dos processos e levantar sugestões junto aos usuários.

Realizou-se pesquisa bibliográfica e eletrônica, em livros, periódicos e endereços eletrônicos pertinentes ao assunto, bem como observação in loco. Pretendeu-se detectar as melhores práticas para dinamizar o papel da biblioteca, inová-la, atender com mais qualidade ao público em geral.
Como amostra aplicou-se 55 (cinquenta e cinco) questionários a servidores lotados na unidade administrativa de uma instituição pública do ramo agropecuário, que utilizam os serviços e produtos da biblioteca.

Com relação a dados complementares buscaram-se informações relativas à Biblioteca Nacional de Agricultura e outras bibliotecas inseridas no âmbito da Assistência Técnica e Extensão Rural.

Depois disso pôde-se traçar planos contínuos de ação contemplando todos os aspectos da qualidade dos produtos/serviços oferecidos pela biblioteca em questão. Havendo observado essa unidade de informação durante onze anos voltam-se agora em 2018 esforços para verificar se houve mudança significativa desse quadro.

\section{QUALIDADE}

De acordo com a ISO 9000, a qualidade pode ser entendida como "o grau em que o conjunto de características inerentes de um objeto satisfaz requisitos".(ABNT, 2015, p.21)

Neste caso, a biblioteca deve tentar oferecer variadas opções em materiais informacionais ou serviços para que o cliente se sinta satisfeito. Com esse objetivo, torna-se factível saber entrevistá-lo a respeito de suas expectativas com relação aos produtos e serviços que possam atendê-lo com precisão.

\subsection{QUALIDADE TOTAL \\ 2.1.1 Conceitos}

Segundo a Academia Pearson $(2011$, p.4) pela Qualidade Total busca-se fazer "melhor, com menos custo, entregando aos clientes produtos que atendam as expectativas ou as superem". E as bibliotecas como prestadoras de serviços originaram a denominação cliente em substituição ao termo usuário. Sejam usuários ou clientes, eles são exigentes e esperam receber do profissional que os atende produtos/serviços de qualidade.

\subsubsection{Aplicações remotas das normas de qualidade}

Segundo Drummond (1998) a aplicação de normas de qualidade foi adotada pela primeira vez por indústrias de defesa na Grã-Bretanha e nos Estados Unidos no início do século XX. Tais normas destinavam-se ao fornecimento de produtos manufaturados de acordo com especificações bem definidas no intuito de 
reduzir despesas com a produção. Nessa época, despendia-se atenção nas especificações técnicas e não no sistema de produção.

Até a década de 40 (quarenta) o foco estava na produtividade. Entre as décadas de 50 (cinquenta) e 70 (setenta) a preocupação ainda era com os produtos físicos. Somente na década de 80 (oitenta) iniciou-se a preocupação com as necessidades dos clientes. Hoje as organizações mantêm a preocupação com a velocidade e a flexibilidade, estando cada vez mais conscientes de que a ênfase para melhorias dos serviços concentra esforços para operar continuamente a satisfação de seus clientes.

Aplicando-se às bibliotecas, o controle da qualidade se realiza por meio de levantamento de opiniões, e balanços estatísticos do uso de produtos/serviços informacionais. Para monitorar esta qualidade elaboram-se continuamente relatórios bem como se observam fatos inerentes ao ambiente da biblioteca.

Dentre as várias filosofias gerenciais para a gestão da qualidade, Deming (apud LONGO; VERGUEIRO, 2003, p.45) apontam como método o ciclo Plan, Do, Check e Act (PDCA), que significa:

Planejamento (P), execução (d), verificação e avaliação (C) e ações corretivas tomadas quando necessário (A). Esta filosofia é visualizada através da figura que representa a visão holística das organizações, tendo como centro o cliente.

Imagine um triângulo equilátero, com um círculo central representando o cliente. Cada vértice indica o que fazer, como, e quem fará.

Deve-se ressaltar que o processo eficaz de mudança só é possível se o aperfeiçoamento desses vértices for contínuo e conjunto, pois eles se referem à qualidade no processo de trabalho.

As empresas estão cada vez mais conscientes de que a ênfase para melhorias dos serviços concentre esforços não em produtividade, que foi o foco até a década de 40, mas na velocidade e flexibilidade no atendimento das necessidades dos clientes. Entre os anos 50 e 70 a preocupação ainda era com a qualidade dos produtos físicos. Somente na década de 80 iniciou-se a preocupação com as necessidades dos clientes.

Atualmente o principal avaliador da qualidade de produtos/serviços não é mais o inspetor, e sim o próprio consumidor. Para um produto ser aceito no mercado precisa ser testado e aceito pelos usuários em potencial. Estes também são importantes para que novos usuários assimilem a ideia e se tornem compradores efetivos. Por isso há empresas que oferecem produtos/serviços novos com alguma forma de controle de opiniões para saber o nível de aceitação que aquele produto/serviço obteve, associado à resposta aos anseios dos usuários.

\subsubsection{Sistema de qualidade}

Conforme a norma ISO 9000, um sistema de gestão da qualidade são as "atividades coordenadas para dirigir e controlar uma organização" (ABNT, 2005, p.9). De forma que se consiga administrar seus bens e serviços para alcançar a excelência e satisfazer o cliente.

Quando um sistema de gestão é baseado na qualidade há aspectos que são observados como: objetivo fundamental: a satisfazer totalmente o cliente; ter melhoria contínua da qualidade, da produtividade e da adaptabilidade; praticar a administração por liderança, promover a participação de todos os funcionários e promover a gestão participativa; focar na melhoria dos processos, por meio da utilização do método científico e visão sistêmica. (ALENTEJO E BAPTISTA, 2012, p.135).

Nesse contexto, é de suma importância a conscientização da alta gerência para realizar a melhoria contínua dos serviços meios e fins de uma biblioteca. Desta maneira, contribuindo para a prática da missão institucional.

Conforme Valls (1998) os sistemas de qualidade são divididos em 5 tipos a saber: manuais da qualidade, políticas de qualidade, procedimentos, instruções de trabalho, e registros da qualidade. Trataremos cada um deles resumidamente.

Manual da qualidade - declara a política de qualidade e descreve o sistema de qualidade de uma organização. Este serve como base referencial para atualizações do sistema de qualidade.

Política de qualidade: refere-se às intenções e diretrizes globais de uma organização 
expressos pela alta gerência no âmbito da qualidade.

Procedimentos - documento que direciona a execução das atividades, com base nas diretrizes contidas no manual da qualidade. Situa os funcionários a respeito de responsabilidades para executar uma tarefa, pois neste documento há definição do que deve ser feito, quando, onde e por quem. Exemplificam-se para este caso, os planos de trabalho, ou ações.

Instruções de trabalho - definição detalhada dos processos a serem executados como exemplo, fluxogramas e manuais de serviços com explicações para realizar uma tarefa, passo a passo.

Registros de qualidade - documento de acompanhamento das atividades realizadas ou resultados obtidos. Objetiva demonstrar resultados, rastrear condições do produto em determinado momento, e propor ações corretivas quando necessário.

\subsubsection{Qualidade no atendimento ao cliente}

De acordo com Tschohl (1996, p.95), "pessoas motivadas consideram os seguintes fatores relevantes para o sucesso em seu trabalho: amizade, espírito de equipe, contato humano com diversas pessoas, e oportunidade de progresso". É primordial que se goste do que faz, isto trará o comprometimento para fazer o trabalho bem. Também é importante reconhecer o esforço do funcionário $\mathrm{e}$ proporcionar-lhe algum tipo de recompensa, caso contrário os níveis de qualidade tendem a diminuir, gerando atrasos nos processos.

$\mathrm{O}$ autor ainda ressalta a importância de tratar o cliente como gostaria de ser tratado. Nesse sentido, é importante reconhecer as pessoas pelo nome, sorrir sempre, olhar em seus olhos e tratá-las com cortesia e respeito

\subsubsection{Satisfação do cliente}

Oliveira (1994, p.15) alerta para a questão da satisfação do cliente quando diz "o que ele espera pode ser aumentado oferecendo mais do que ele pensa necessitar ou do que costuma esperar". Pode-se perceber claramente quando um usuário se sente satisfeito pela expressão de seus pensamentos. Deve-se surpreendê-lo procurando não somente disponibilizar-lhe o que pediu, mas proporcionar um leque de suportes que atendam às suas necessidades informacionais.
Para tanto, faz-se oportuno desenvolver e aplicar um programa de qualidade, que abranja melhoria do ambiente de trabalho, tornando-o mais agradável e motivador das relações cooperativas, de modo que se obtenham ideias e sugestões, bem como comprometimento de cada indivíduo para melhorar os serviços oferecidos à comunidade atendida pela biblioteca. "Fazendo mais do que só o suficiente, você progredirá em seu trabalho, ganhar satisfação e se sentir muito bem consigo mesmo". (TSCHOHL, 1993, p. 91)

\subsubsection{Satisfação do usuário nas bibliotecas}

Segundo Belluzzo e Macedo (1993, p. 126127) "encorajar os usuários a avaliar constantemente os serviços oferecidos pela biblioteca é uma das abordagens mais úteis para se encontrar as evidências que nortearão a melhoria da qualidade".

Tal afirmativa vem ao encontro da iniciativa deste trabalho, que busca a participação dos usuários nas ações de qualidade para a biblioteca.

Vale salientar que para se preocupar em satisfazer os clientes, os funcionários, servidores ou colaboradores precisam estar satisfeitos em suas necessidades básicas individuais (fome, frio, segurança, etc.), ou seja, é essencial garantir melhores condições de vida para o cliente interno da organização. Caso contrário o nível de cooperação e interação será mínimo, pois mais importante do que satisfação, maquinário moderno, é a organização, a dedicação dos funcionários com foco no cliente. "Instalações físicas e equipamentos, por mais sofisticados que sejam não funcionam independente das mãos que os operam" (LONGO, VERGUEIRO, 2003, p.43).

No entanto sabe-se que satisfazer as necessidades individuais dos funcionários requer melhorias coletivas que contemplem entre outros fatores os seguintes pontos: completude do plano de cargos e salários, sistema de recompensas, treinamento e capacitação dos servidores, oferecimento de um sistema de saúde e práticas de atividades de lazer, exercícios de relaxamento no ambiente de trabalho. Nesse sentido, aumentando-se a qualidade de vida dos funcionários, se propiciará o aumento de seu rendimento no trabalho. 


\section{BIBLIOTECA ESPECIALIZADA}

\subsection{ALGUMAS CARACTERÍSTICAS}

Voltadas a um campo específico do conhecimento, seu acervo e seus serviços atendem às necessidades de informação e pesquisa de usuários interessados em uma ou mais áreas específicas do conhecimento. (SNBP, 2017).

Isso autoriza concluir que a biblioteca especializada trabalha com informação técnica, insumo da implementação das tarefas mais complexas de uma empresa. De modo semelhante à situação exemplificada acima, os pesquisadores que utilizam os insumos informacionais da biblioteca da EMATER-RN procuram documentos passíveis de servirem de base para a formulação de propostas de melhorias sejam em nível técnico, operacional ou tático de modo que possibilite a capacitação respectivamente de extensionistas e agricultores familiares.

As Bibliotecas Especializadas orientam-se para a construção do conhecimento de determinado público. Nesta ótica, bibliotecas pertencentes ao setor agropecuário quando fornecem informações relevantes para o apoio técnico e extensão rural, auxiliam técnicos, extensionistas e educadores, contribuindo para a atualização de conhecimentos técnicos dos servidores vislumbrando aprimorar o programa de transferência de tecnologia para agricultores que procuram maximizar o rendimento e a qualidade dos produtos agrícolas com a execução de métodos essenciais.

Também podem cooperar com as bibliotecas de caráter volante alcançando comunidades carentes, que se deparam com a maravilha do mundo mágico da leitura. Dentro deste perfil, pode-se exemplificar a Arca das Letras, Projeto que leva ao agricultor rural e sua família, após alfabetizados, um conjunto de livros com diversos assuntos objetivando incentivar o hábito da leitura e reflexão. A arca permanece na casa do agricultor por um período determinado, e logo passa a outro, desta forma dinamizando a aprendizagem comunitária.

Nesse sentido, Curvo Filho (1979, p.38) afirmou no século passado que:

[...] numa era de explosão bibliográfica, não se concebe o desenvolvimento sem a organização de sistemas de informação que permitam a coleta, processamento, armazenamento, recuperação e difusão de dados documentários, fazendo com que todos os técnicos envolvidos com determinado problema tenham acesso fácil às informações necessárias para que eles possam se atualizar constantemente, criar e transferir tecnologias e tomar decisões adequadas.

Mas para que isso ocorra é necessário fazer uso das novas tecnologias de informação, de modo que minimize o tempo de espera na disseminação para os produtos informacionais. Para tanto, as informações precisam ser confiáveis, rápidas, pertinentes, acuradas, oportunas, atuais, acessíveis, e adequadas às necessidades dos usuários.

\section{A BIBLIOTECA NACIONAL DE AGRICULTURA}

Criada em 18 de novembro de 1909 pelo então ministro da Agricultura, Indústria e Comércio, Antônio Cândido Rodrigues, a Seção de Publicações e Bibliotheca [sic], hoje, Biblioteca Nacional de Agricultura (Binagri) completará 109 anos no dia 18 de novembro de 2018. (BRASIL, 2015a apud MCDONNELL, 2015, p.25)

Para suprir as necessidades informacionais do produtor rural e este adotar práticas culturais relacionadas ao seu contexto regional, visando o aumento da produtividade agrícola, surge em 1938, o Serviço de Informação Agrícola (SIA) ligado ao ministério da Agricultura, Indústria e Comércio, criado para atender à área rural divulgando os feitos do governo e transferindo tecnologia para o homem do campo.

Mais tarde (1972), visando reunir a informação agrícola nacional, o governo brasileiro encaminha às Nações Unidas, uma solicitação de assistência técnica para a criação de um centro de informação e documentação agrícola.

No ano seguinte, depois de realizado o diagnóstico com a ajuda da FAO sobre a situação da documentação e informação agrícola no Brasil, elabora-se um Projeto para a criação do Sistema Nacional de Informação e Documentação (SNIDA). Foi implantado em janeiro de 1974. Sob a responsabilidade da Coordenadoria de Informação Rural (CIR), órgão da Secretaria Geral, ao qual é vinculada a Biblioteca Central do Ministério da 
Agricultura (BICEN). A CIR, após um ano, transfere à implantação do Projeto para a Empresa Brasileira de Assistência e Extensão Rural (EMBRATER), com o termo de ajuste firmado entre esta empresa e o Ministério da Agricultura.

O projeto do SNIDA foi administrado pela EMBRATER durante três anos. Após este prazo, institucionalizou-se a unidade de coordenação do Sistema com a criação da Biblioteca Nacional de Agricultura (BINAGRI), através da Portaria Ministerial ${ }^{\circ}$ 325, de 28 de abril de 1978.

Quatro anos mais tarde, através da Portaria Ministerial ${ }^{\circ}$ 287, de 21 de outubro de 1982, passa a ser Centro Nacional de Informação e Documentação Agrícola (CENAGRI). Com a mesma sigla e instituição de portarias bem como anos diferentes também se denominou Coordenadoria Agrícola, além de Coordenadoria- Geral de Informação Documental Agrícola.

Finalmente, através do Decreto $\mathrm{n}^{\circ} 5.351$, de 21 de janeiro de 2005, vinculada diretamente à Secretaria Executiva do Ministério da Agricultura, Pecuária e Abastecimento, volta à denominação Biblioteca Nacional de Agricultura (BINAGRI, 2018).

\subsection{FUNÇÃO}

A Biblioteca Nacional de Agricultura (BINAGRI) reúne a produção intelectual sobre agropecuária no Brasil. Afere-se a mesma as atividades de coleta, processamento, armazenamento e disseminação de informação científica e tecnológica de interesse do setor agrícola e áreas correlatas, garantindo a preservação da memória agrícola nacional. Também funciona como ponte entre bibliotecas especializadas em agropecuária, visto que realiza intercâmbio informacional com outras bibliotecas tanto em nível nacional como internacional.

\subsection{LOCALIZAÇÃO}

A Biblioteca Nacional de Agricultura (BINAGRI) subordina-se à Secretaria Executiva (SE) do Ministério da Agricultura, Pecuária e Abastecimento (MAPA), na

Esplanada dos Ministérios, BL D, Anexo B, Térreo. Para envio de correspondências, sua Caixa Postal é 02432, CEP 70849970 Brasília-DF.

\section{ESTUDO DE CASO DE UMA BIBLIOTECA ESPECIALIZADA EM AGROPECUÁRIA NO RN \\ 5.1 CARACTERIZAÇÃO DA INSTITUIÇÃO}

A Associação Nordestina de Crédito e Assistência Rural (ANCAR), pioneira no Serviço de Assistência Técnica e Extensão Rural, no Estado do Rio Grande do Norte, foi criada em 27 de julho de 1955, nos Municípios de Currais Novos, Santa Cruz, São Tomé, e São Paulo do Potengi, sendo coordenada pela ANCAR regional, esta sediada em Recife-PE, cuja proposta de ação visava o desenvolvimento socioeconômico do homem do campo. A ANCAR posteriormente veio a se chamar Empresa de Assistência Técnica e Extensão Rural (EMATER-RN), entidade pública de direito privado criada através da Lei Estadual $n^{\circ} .4 .484$ de 23 de setembro de 1975, vinculada à Secretaria de Agricultura (SAG), denominação da época.

Em 1993 através da Lei número 6.486, de 5 de outubro de 1993, a Assembleia Legislativa transformou a EMATER-RN em autarquia, passando a chamar-se Instituto de Assistência Técnica e Extensão Rural do Rio Grande do Norte (INATERN), competente para conceber e executar a política de assistência técnica e extensão rural do Estado, com atividades voltadas para a agricultura, pecuária, saúde e agroindústria. Ainda de acordo com a Lei, cabia ao INATERN a orientação, acompanhamento e avaliação dos projetos de crédito rural, a execução de ações de preservação e recuperação do meio ambiente, das políticas agrícolas, além do treinamento de produtores nas diversas atividades inerentes ao negócio agrícola.

Com estas mesmas atribuições, a partir de 2 de fevereiro de 1995 o INATERN passou a se chamar EMATER-RN, nova denominação dada ao Instituto por força da Lei Complementar $\mathrm{n}^{\circ} 129$, situação esta que perdura até hoje.

\subsubsection{A Biblioteca da EMATER-RN}

É uma biblioteca especializada em Agropecuária, localizada às margens da $\mathrm{BR}$ 101 do Km 0, BL-6 - Centro Administrativo do Estado, no bairro de Lagoa Nova, em Natal RN, com CEP: 59064-901, e funcionando de segunda a sexta-feira, das 7 às $15 \mathrm{~h}$. É subordinada à Coordenadoria de Planejamento 
e Execução (COPE). Foi criada na década de setenta, inicialmente com denominação, Núcleo de Informação e Documentação (NIDOC), com vistas a atender demandas informacionais do Setor agropecuário e dar suporte às atividades de Assistência Técnica e Extensão Rural (ATER).

Na década de oitenta, associada ao Sistema de Informação da EMBRATER, operava com dez minibibliotecas inseridas em número igual de unidades regionais distribuídas pelo interior do Estado. Hoje essa estrutura encontra-se em planos de repaginação para atender à demanda informacional tanto do público formado por técnicos da Instituição bem como de áreas afins à agropecuária.

\subsubsection{Missão}

A missão da Biblioteca da EMATER-RN é disponibilizar a todos os servidores da autarquia e entidades afins, informações sobre agropecuária e demais estudos literários em benefício do público em geral.

\subsubsection{Função}

Com efeito, a biblioteca da EMATER-RN realiza seu papel no apoio à formulação de planos, projetos, propostas, relatórios, livros, folhetos, "folders", "banners", apostilas, regimentos, jornal institucional e outros documentos através da seleção, aquisição, tratamento técnico, divulgação e disponibilização de materiais informacionais, objetivando melhor atender o agricultor familiar por meio dos extensionistas rurais, que são os principais usuários do acervo da referida biblioteca.

\subsubsection{Público-alvo}

Além dos técnicos agropecuários, a biblioteca da EMATER-RN atende ao público em geral, normalmente estudantes do ensino fundamental ao superior e parceiros da instituição. Tais usuários procuram principalmente por materiais informacionais que contenham informações sobre culturas e criações diversas. Podem-se destacar como usuários potenciais alunos da Universidade Federal do Rio Grande do Norte (UFRN) e Universidade Federal Rural do Semiárido (UFERSA).

Além de materiais informacionais da área agropecuária, formado por cartazes, folders, folhetos, periódicos, multimeios, livros, e banners, o acervo abrange um percentual mínimo de outras áreas do conhecimento humano conforme Quadro 1 a seguir:

Quadro 1 - Assuntos que o acervo possui

\begin{tabular}{|l|l|}
\hline Administração agrícola, empresarial, industrial, & Cunicultura, Drenagens, Ecologia, Economia, \\
Adubos e fertilizantes & Educação, Energia \\
Alimentos - nutrição e/ou preparo & Entomologia, Equinocultura, Extensão rural, Genética \\
anima, Geologia, Hidrologia, Irrigação, Mecanização & agrícola, Ovinocultura, Pedologia \\
Avicultura, Armazenagem/ grãos & Piscicultura, Plantas medicinais e/ou têxteis, \\
Carcinicultura, Ciências médicas e sociais & Ranicultura, Saneamento \\
Comercialização Agrícola, Comunicação & Serviço Social, Silvicultura, Suinocultura \\
$\begin{array}{l}\text { Construções rurais, Contabilidade } \\
\text { Culturas diversas (abacate, abacaxi, acerola, } \\
\text { algaroba, algodão, amendoim, arroz, banana, cacau, } \\
\text { cana - de- açúcar, café, caju, castanha, cebola, citros, } \\
\text { coco, feijão, fumo, gergelim, girassol, goiaba, } \\
\text { graviola, inhame, jojoba, licuri, maçã, manga, } \\
\text { mamão, mamona, maracujá, melão, melancia, milho, } \\
\text { mandioca, pêssego, pimenta, pupunha, sisal, soja, } \\
\text { sorgo, tomate, trigo, urucum, uva) }\end{array}$ \\
\end{tabular}

Fonte: Levantamento interno (2007- 2018)

\subsubsection{Marketing informacional}

Para divulgar os produtos/serviços oferecidos pela biblioteca, além da chegada de itens informacionais, são utilizados os seguintes meios de comunicação: facebook,
WhatsApp, folder, regimento interno, lista de novas aquisições, e informail, que é a disseminação de informações por e-mail compartilhamento via drive. 


\subsubsection{Recursos humanos}

A biblioteca possui em seu quadro funcional dois bolsistas e dois servidores efetivos. Sendo três dessas pessoas Bacharéis em Biblioteconomia. O outro componente da equipe é biólogo.

Percebe-se a constante necessidade da contratação e manutenção de estagiários e/ou bolsistas do Curso de Biblioteconomia, com o objetivo de suprir deficiências relativas ao acúmulo de materiais informacionais sem tratamento técnico ao longo dos anos, em virtude da falta de pessoal.

\subsubsection{Recursos tecnológicos}

Durante muitos anos, pela dificuldade inerente ao setor público a biblioteca operou com escassez de recursos tecnológicos apropriados ao desenvolvimento de suas tarefas. Hoje, conta com dois computadores, impressora laser, leitor ótico, teclado especial e um scanner de mesa. Para maximizar a função desses equipamentos, adquiriu-se o Sistema de Automação de Bibliotecas (SIABI), um software para gerenciar informações captadas e contidas pela biblioteca. Isso se deve ao fato de que existe na EMATER-RN a consciência de que o processo de desenvolvimento do produtor rural, as decisões na área econômica, o comportamento e controle dos planos, projetos e programas requerem um sistema de informação amplo e oportuno capaz de subsidiar a tomada de decisões. Nesse sentido, o SIABI representa uma ferramenta de grande utilidade no gerenciamento de todos os processos de uma biblioteca.

\subsubsection{Serviços}

Entre os serviços que a biblioteca oferece destacam-se: Atendimento a consulta e empréstimos; Elaboração de boletins bibliográficos; Levantamentos Bibliográficos; Disseminação das publicações da EMATERRN; Normalização de documentos (ABNT), e Intercâmbio/ doação de documentos.

Para utilizar tais serviços e produtos informacionais é necessário pertencer ao quadro funcional da EMATER-RN e dos parceiros ematerianos, cadastrar-se na Biblioteca, contribuir para a conservação do acervo, cumprir o prazo estabelecido durante o empréstimo; e no caso de perda ou extravio do material que lhe foi emprestado, responsabilizar-se por sua reposição. E caso esgotada a edição do item, doar um de teor semelhante. Por fim, respeitar os funcionários e estagiários deste setor.

Diante do número de itens informacionais acumulados ao longo dos anos, realizam-se poucos serviços utilizando-se considerável espaço de tempo. Desta forma, demora-se um pouco para começar um novo serviço.

Além disso, faz-se necessário acrescer novos equipamentos e recursos humanos para atender aos fins e missão propostos pela empresa mantenedora da biblioteca.

\subsubsection{Práticas inovadoras para incentivar o uso dos produtos e serviços da biblioteca}

A incorporação de novos produtos/serviços ajustando-se ao avanço técnico informacional auxilia as bibliotecas na busca da satisfação de seus usuários.

Para tanto, segundo Barbêdo e Vergueiro (2006), faz-se necessário:

- Aplicar um sistema de gestão da qualidade em bibliotecas de modo que contribua para melhorar a organização interna

- Definição clara e documentada das atividades e responsabilidades

- Melhor fortalecimento da competência e qualidade do trabalho

- Melhor imagem da biblioteca

- Motivação e maior dedicação bem como desenvolvimento de atividades, atendendo as necessidades de seus usuários

Entretanto, mudar paradigmas de uma biblioteca que se encontrava deficiente em vários aspectos, inclusive falta de estagiários da área de biblioteconomia, não acontece da noite para o dia, envolve paciência, investimento em capacitação profissional, recursos tecnológicos e constante aperfeiçoamento dos processos de trabalho. Além destes fatores, muitas vezes uma empresa pública não dispõe de recursos apropriados para contratar estagiários por fatores burocráticos, ou seja, no caso da instituição diagnosticada, ela depende de recursos dos Governos Federal e Estadual, da aprovação de projetos sociais que beneficiem diretamente o agricultor. Neste sentido, é difícil conseguir recursos para modernizar a unidade de informação em questão, pois não há recurso financeiro específico para ela. 
Segundo Andrade [s.d.], para alcançar a excelência nos serviços prestados, a biblioteca precisa inovar, melhorar formas de atendimento e processos de trabalho bem como levantar as necessidades de seus recursos humanos. Nesse sentido, é crescente o compromisso e responsabilidade perante a comunidade beneficiada, os usuários. Sob essa ótica, os novos paradigmas informacionais impulsionam à incorporação de práticas inovadoras aliadas às funções tradicionais, para direcionar as organizações ao processo de transformação, tendo como foco o cliente.

Para Monteiro (1991, p.10):

Inovar não significa criar produtos e serviços novos. Inovar significa atualizar os produtos e serviços, de forma que a sociedade seja cada vez melhor atendida. Só é possível inovar quando se pensa no futuro; não é possível pensar no futuro sem se questionar a cada passo para que sirva a organização.

Nessa perspectiva, segundo Tarapanof (2001), a ascensão econômica e social está ligada ao domínio que as pessoas têm sobre o conhecimento, pois podem planejar a inovação.

Partindo desse pressuposto, a utilização de produtos/serviços da biblioteca da EMATERRN pode ser maximizada modernizando-se suas práticas e implementando-se a divulgação deles por meio de: quadro de avisos (mural), envelope padronizado, contadores de visitas on-line, camisetas padronizadas para usar na semana do livro, hiperlink de acesso direto a sites que disponibilizam o serviço de comutação, canetas com informações de localização da biblioteca e formas de contato, banner com as principais informações sobre a biblioteca, vídeo informativo, disponibilização de formulário on line para solicitar empréstimo entre bibliotecas com tutorial, formulário on line para solicitar levantamento bibliográfico, sacolas padronizadas, marca página, boletins informativos on line, alerta eletrônico, calendário, acesso ao catálogo on line, e criação de um link para a biblioteca na home page da EMATER-RN.

Segundo Oliveira (1994) o marketing informacional faz com que o cliente conheça e assimile novos itens informacionais.

\section{ANÁLISE DOS DADOS}

Baseado em questionário aplicado a 55 servidores da EMATER-RN buscou-se rever e melhorar processos de trabalho com vistas maximizar o uso de produtos e serviços da biblioteca desta autarquia.

Depois de realizada pesquisa por meio de questionário, notou-se maior demanda para o serviço de empréstimo domiciliar (33\%).

Dos serviços sugeridos para oferecimento elencaram como prioritário o serviço de videoteca $(27 \%)$. E o principal ponto para melhorá-la, a atualização de seu acervo (36\%). Hoje nota-se, além disso, a reestruturação do layout.

Quanto à qualidade das informações fornecidas pela biblioteca da EMATER-RN, dados revelaram que são precisas, seguras $(94,54 \%)$ e consistentes $(94,44 \%)$. Além desses fatores, verificou-se que os funcionários atendem aos usuários com prontidão (89\%), e em tempo satisfatório (78\%), com empatia. Por isso o tratamento dispensado aos usuários é considerado cordial, e os serviços são adaptados às suas necessidades informacionais.

$43(78 \%)$ das pessoas responderam que preferem obras mais atualizadas, tendo bibliografia pessoal disponível em casa.

A maioria dos usuários informou que o motivo maior para não se frequentar a biblioteca é a falta de tempo.

\section{CONSIDERAÇÕES FINAIS E RECOMENDAÇÕES}

Para aumentar a frequência dos usuários na biblioteca sugerem-se o apoio dos setores: coordenação a qual a biblioteca é subordinada, diretoria, financeiro e jornalístico da instituição mantenedora, para a criação dos meios de divulgação elencados neste trabalho tais quais: calendário, quadro de avisos (mural), envelope padronizado, camisetas padronizadas para usar na semana do livro, canetas com informações de localização da biblioteca e formas de contato, sacolas padronizadas, marca página, vídeo informativo, banner com as principais informações sobre a biblioteca. Além dos meios tradicionais, alguns on line: contadores de visitas, hiperlink de acesso direto a sites que disponibilizam o serviço de comutação, disponibilização de formulário para solicitar empréstimo entre bibliotecas com tutorial, para solicitar levantamento bibliográfico, 
boletim informativo, alerta eletrônico, acesso ao catálogo, e criação de um link para a biblioteca na home page da EMATER-RN.
Quanto aos demais pontos se faz oportuno que a instituição disponibilize recursos para criar uma videoteca.

\title{
PERCEPTIONS OF THE QUALITY OF SERVICES AND INFORMATIONAL PRODUCTS OF A LIBRARY SPECIALIZING IN AGRICULTURE: A CASE STUDY
}

\begin{abstract}
The quality of services and products is important in any field of activity. Libraries are no different. To reach this understanding it was important to bring to this article concepts of library, quality, total quality and specialized library. Soon after, historical and location aspects are listed on the national agricultural library, seeking to inform the main source of collections on agriculture in Brazil. And in the state of Rio Grande do Norte, a case study was carried out with the main purpose of verifying if a library specialized in agriculture and livestock reaches its main objective: meeting the informational needs of the target public, with services and quality products. As part of the methodology, questionnaires were applied to 55 (fifty-five) servers belonging to the staff of the municipality that maintains the information unit on screen, as well as bibliographic / electronic research. The statistical analysis was by means of proportions. As a result, it was found that the quality of the provision of information products and services was partially satisfactory. The study of this case becomes relevant because it is a landmark to review and improve work processes with a view to maximizing the use of informational services and products.
\end{abstract}

Keywords: Total quality - Product and services Information. Specialized Library-Agricultural.

\section{REFERÊNCIAS}

ASSOCIAÇÃO BRASILEIRA DE

NORMAS TÉCNICAS. Sistemas de gestão

da qualidade: fundamentos e vocabulário:

NBR ISO 9000. 2 ed. Rio de Janeiro, 2015.

ACADEMIA PEARSON. Gestão da qualidade. São Paulo: Pearson Education do Brasil, 2011.

ALENTEJO, Eduardo da Silva; BAPTISTA, Sofia Galvão. A trajetória da gestão pela qualidade nas bibliotecas brasileiras.

Informação \& Informação, Londrina, v. 17, n. 1, p. 132-163, ja./jun. 2012.

ANDRADE, Maria Teresinha Dias de. Mudanças e inovações: novo modelo de organização e gestão de biblioteca acadêmica: relatos de experiências. Disponível em: < http://www.scielo.br/pdf/ci/v27n3/27n3a09.pd f>. Acesso em: 30 abr. 2017.

BARBÊDO, Simone Angélica Del - Ducca; VERGUEIRO, Waldomiro. Qualidade em bibliotecas universitárias da área pública: a contribuição do gespública. In: SEMINÁRIO NACIONAL DE BIBLIOTECAS UNIVERSITÁRIAS. 14., 2006, Salvador. Anais...Salvador: INPE, 2006. Disponível em: < http://mtcm16.sid.inpe.br/col/sid.inpe.br/mtcm16\%4080/2006/10.31.16.31/doc/Simone.pd f>. Acesso em: 30 mar. 2018.

BELLUZZO, R. C. B., MACEDO, N.D. A gestão da qualidade em serviços de informação: contribuição para uma base teórica. Ciência da Informação, Brasília, v. 22, n. 2. p. 126-127, 129, maio - ago. 1993. 
BINAGRI. História. Brasília: DF, MAPA, 2016. Disponível em:

$<$ http://www.agricultura.gov.br/biblioteca/hist oria>. Acesso em: 10 jan. 2018.

CARAVANTES, Geraldo R.;

CARAVANTES, Cláudia; BJUR, Wesley.

Administração e qualidade: a superação dos desafios. São Paulo: Makron Books, 1997.

CURVO FILHO, Plácido Flaviano. Informação e documentação agrícola na comunicação rural. Ciência da Informação. Rio de Janeiro, v.8, n.1, p.37 - 46, 1979.

DRUMOND, H. Movimento pela qualidade: de que o gerenciamento de qualidade total realmente Trata. São Paulo: Littera Mundi, 1998.

FERREIRA, Aurélio Buarque de Holanda. Novo dicionário Aurélio da língua portuguesa. 2.ed. rev. e amp. Rio de Janeiro: Nova Fronteira, 1986.

LOBOS, Julio. Qualidade! através das pessoas. São Paulo: J.Lobos, 1991.

LONGO, Rose Mary Juliano; VERGUEIRO, Waldomiro. Gestão da qualidade em serviços de informação do setor público:

características e dificuldades para sua implantação. Revista Digital de Biblioteconomia e Ciência da Informação. Campinas, v.1, n.1, p. 39- 59, jul. - dez. 2003.

MCDONNELL, Mariana Bessa. O histórico da Biblioteca Nacional de Agricultura como unidade central de uma rede de informação agrícola no Brasil. 2015. 90f. Monografia (Graduação) - Universidade de Brasília, Faculdade de Ciência da Informação, Brasília, DF.

MONTEIRO, José A. Qualidade total no serviço público: questionamentos e recomendações seguindo os 14 pontos de W.E. Deming. Brasília: QA\& T Consultores e Associados, 1991.

OAKLAND, J. Gerenciamento da qualidade total. São Paulo: Nobel, 1994.
SANTOS, Edilene Galdino dos; LIMA, Izabel França de; ABRANTES, Mônica Paiva Santos de. Gerenciamento da rotina diária em unidades de informação. Disponível em: <http://dici.ibict.br>. Acesso em: 25 fev.2018.

SISTEMA NACIONAL DE BIBLIOTECAS PÚBLICAS. Tipos de bibliotecas: biblioteca especializada. Disponível em:< http://snbp.culturadigital.br/tipos-debibliotecas/>. Acesso em: 20 mar. 2018.

TARAPANOF, Kira (Org.) Inteligência organizacional e competitiva. Brasília: DF, UNB, 2001.

TSCHOHL, John. Encantando o cliente. São Paulo: Macron Books, 1996.

VALLS, Valéria Martin. O bibliotecário como gerenciador dos documentos do sistema de qualidade. Informação \& Informação, Londrina, v.3, n.1, p.33- 44, jan. - jun. 1998. 